\title{
Color stability after accelerated aging of two silicones, pigmented or not, for use in facial prostheses
}

\section{Daniela Nardi Mancuso(a) Marcelo Coelho Goiato(b) Daniela Micheline dos Santos ${ }^{(a)}$}

(a) PhD Student; (b) Professor - Department of Dental Materials and Prosthodontics, School of Dentistry of Araçatuba, São Paulo State University, Araçatuba, SP, Brazil.

\section{Corresponding author:}

Marcelo Coelho Goiato

Faculdade de Odontologia de Araçatuba, UNESP

Departamento de Materiais Odontológicos e Prótese

Rua José Bonifácio, 1193, Vila Mendonça Araçatuba - SP - Brazil

CEP: 16015-050

E-mail:goiato@foa.unesp.br

\begin{abstract}
One of the greatest challenges faced by buccomaxillofacial prosthetists is to reproduce the patient's exact skin color and provide adequate esthetics. To reach this objective, professionals must use materials with easy characterization and that maintain color over long periods of time. The objective of this study was, thus, to evaluate the color stability of two types of silicones, Silastic 732 and Silastic MDX4-4210. Twenty-four test specimens were made from each type of silicone and were divided into a colorless group and groups intrinsically pigmented with ceramics, cosmetics or iron oxide. The specimens were submitted to an accelerated system of aging for non-metallic materials. Readings were carried out initially and after periods corresponding to 163, 351, 692 and 1,000 hours of aging, using a reflection spectrophotometer analysis, and color alterations were calculated by the CIE L*a*b* system. The data were submitted to variance analysis and Tukey's test at a 5\% level of probability. The results demonstrated that, irrespective of the period of time analyzed, all the materials underwent some type of chromatic alteration $(\Delta \mathrm{E}>0)$. The test specimens made with Silastic 732 and MDX44210, without pigmentation, presented the lowest color alteration values after 1,000 hours of aging. Of the pigments, ceramic presented the lowest color alteration values and cosmetic powder presented the highest values. Thus, it may be concluded that the materials without the incorporation of pigments presented similar color alteration values, and did not differ statistically. The cosmetic powder used in this study was the pigment that most altered the color of the test specimens.
\end{abstract}

Descriptors: Maxillofacial prosthesis; Silicone elastomers; Pigmentation. 


\section{Introduction}

To make maxillofacial prostheses, the shape, volume, position, texture and transparency of the patient's features must be respected. Although prosthetic technicians usually choose good materials to manufacture prostheses, we have noticed that they have great difficulty in reproducing the color of patients' skins. Owing to the action of external agents, changes in color occur, resulting in prostheses that do not match the patient's skin, hence compromising the dissimulation of the facial defect. ${ }^{1,2}$

In this context, several methods of color pigmentation were tested with the intention of achieving color stability, both for intrinsic and extrinsic color pigmentation, when exposed to external factors. ${ }^{3,4,5}$ Gary, Smith ${ }^{6}$ (1998), however, reported a variety of methods for testing color stability with various pigments, although research lacks regarding the color stability of pigments in maxillofacial elastomers. ${ }^{7}$ Considering the above and taking into account the diversity of materials, pigments and methods to evaluate the color stability of maxillofacial prostheses, this study evaluated, by reflection spectrophotometry, the color stability of silicones, pigmented or not, when employed for facial use after accelerated aging.

\section{Material and Methods Material}

For this study, two types of silicones were used to manufacture the test specimens; one is appropriate for use in facial prostheses (Silastic MDX4-4210; Dow Corning Corporation, Midland, MI, USA); and the other is an acetic silicone developed for industrial use (Silastic 732; Dow Corning do Brasil Ltda., Hortolândia, SP, Brazil). For an intrinsic pigmentation of the silicones, three systems of coloring were used: Cosmetic (Payot, São Paulo, SP, Brazil), ceramic (Clarart, DF, Brazil) and iron oxide (Bayer S.A., São Paulo, SP, Brazil).

\section{Method}

The test specimens master molds were manufactured in white orthodontic plaster (Orto-Rio Produtos Odontológicos, Rio Claro, SP, Brazil) using molds of pink wax 7 (Wilson, Polidental Indústria e
Comércio Ltda., São Paulo, SP, Brazil) with a length of $7 \mathrm{~cm}$, width of $5 \mathrm{~cm}$ and thickness of $2 \mathrm{~mm}$.

Twenty-four test specimens were made for each silicone and were subdivided into groups: Colorless and pigmented with cosmetic powder, iron oxide or ceramic. In addition to the pigments, the silicones were weighed using a precision digital scale (BEL Equipamentos Analítico, Piracicaba, SP, Brazil). The pigment weight was equivalent to $0.2 \%{ }^{8,9}$ of the weight of the silicone (Table 1).

The silicones were handled according to the manufacturer's instructions, i.e., at a room temperature of $23 \pm 2^{\circ} \mathrm{C}$ and relative humidity of $50 \pm 10 \%$. Each pigment was mixed with the silicone on a glass sheet with the help of a stainless steel spatula until an homogenous mixture was obtained. The silicone was then inserted in the master mold and the excess was removed with a spatula to maintain a regular thickness. The Silastic 732 silicone was placed in the master mold with the external surface exposed to room temperature for 24 hours. Silastic MDX44210 was then placed in the master mold with the external surface exposed to room temperature for 3 days. According to the manufacturer's instructions, final polymerization of each silicone occurs during this period. After this period, each test specimen was carefully separated from the metallic master mold and the thickness of $2 \mathrm{~mm}$ was confirmed with a caliper.

The test specimens obtained were submitted to initial chromatic analysis by means of a Visible Ultraviolet Reflection Spectrophotometer, ${ }^{10,11}$ Model

Table 1 - Sub-division of the test specimens.

\begin{tabular}{c|c|c|c}
\hline \multirow{2}{*}{ Silicon Groups } & $\begin{array}{c}\text { Pigment Sub- } \\
\text { Groups }\end{array}$ & $\begin{array}{c}\text { Pigment \% } \\
\text { in Weight }\end{array}$ & $\begin{array}{c}\text { Number of test } \\
\text { specimens }\end{array}$ \\
\hline \multirow{4}{*}{ Silastic 732 } & Colorless & $0 \%$ & 6 \\
\cline { 2 - 4 } & Cosmetic & $0.2 \%$ & 6 \\
\cline { 2 - 4 } & Iron oxide & $0.2 \%$ & 6 \\
\hline \multirow{3}{*}{ Silastic MDX } & Ceramic & $0.2 \%$ & 6 \\
\cline { 2 - 4 } $4-4210$ & Colorless & $0 \%$ & 6 \\
\cline { 2 - 4 } & Iron oxide & $0.2 \%$ & 6 \\
\cline { 2 - 4 } & Ceramic & $0.2 \%$ & 6 \\
\hline
\end{tabular}


UV-2450 (Shimadzu, Kyoto, Japan). The color alterations were calculated using the CIE L*a*b* System, established by the "Commission Internationale de l'Eclairage - CIE". ${ }^{12}$ This system allows the value of $\Delta \mathrm{E}$ (color variation) between two readings to be calculated by means of the formula:

$$
\Delta \mathrm{E}=\left[(\Delta \mathrm{L})^{2}+(\Delta \mathrm{a})^{2}+(\Delta \mathrm{b})^{2}\right]^{1 / 2}
$$

After the first color reading was made, an accelerated aging treatment was carried out by means of an aging chamber (Comexim Matérias Primas Indústria Comércio Ltda., São Paulo, SP, Brasil) for non-metallic specimens, using $\mathrm{UVB} /$ condensation.

The test specimens were submitted to periods of alternate ultraviolet light and condensation of distilled water saturated with oxygen under conditions of heat and $100 \%$ humidity. Each aging cycle was performed for twelve hours. In the first eight hours, ultraviolet light was irradiated at a temperature of $60 \pm 3^{\circ} \mathrm{C}$. In the next four hours, a period of condensation took place without light at a temperature of $45 \pm 3^{\circ} \mathrm{C}$. This process simulated the deterioration caused by rain water, as well as dew and ultraviolet energy (UVB) from direct and indirect sunlight.

The test specimens were exposed to 1,000 hours of accelerated aging, and new readings of chromatic alteration were performed after periods corresponding to $163,351,692$ and 1,000 hours. The $\Delta \mathrm{E}$ values were then submitted to analysis of variance and Tukey's test at a level of probability of $5 \%$.

\section{Results}

The results demonstrated that, irrespective of the time period analyzed, all the materials evaluated underwent some type of chromatic alteration $(\Delta \mathrm{E}>0)$. The test specimens made with Silastic 732 and MDX4-4210 without pigmentation presented the lowest color alteration values after 1,000 hours of accelerated aging (Tables 2, 3).

No statistically significant differences were found between the different aging periods for the test specimens pigmented with ceramic powder, irrespective of the silicone used. However, a statistically significant difference was observed between the color alteration values for the test specimens in both silicones pigmented with cosmetic powder (Tables 2, 3).

\section{Discussion}

According to the results obtained in this study, both Silastic 732 and MDX4-4210, whether pigmented or not, presented color instability $(\Delta \mathrm{E}>0)$, irrespective of the aging period. It is known that this chromatic alteration may be caused by both intrin-

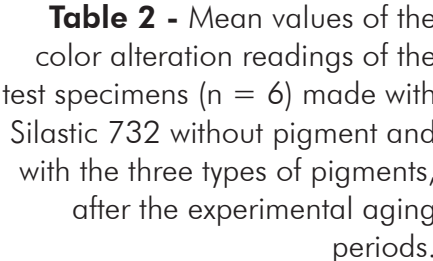

periods.

\begin{tabular}{c|c|c|c|c}
\hline Silastic 732 & $163 \mathrm{~h}$ & $351 \mathrm{~h}$ & $692 \mathrm{~h}$ & $1,000 \mathrm{~h}$ \\
\hline Cosmetic & $0.283 \mathrm{~A}, \mathrm{a}$ & $0.292 \mathrm{~B}, \mathrm{a}$ & $0.513 \mathrm{~A}, \mathrm{~b}$ & $0.545 \mathrm{~A}, \mathrm{~b}$ \\
\hline Iron oxide & $0.445 \mathrm{~A}, \mathrm{ab}$ & $0.235 \mathrm{~B}, \mathrm{~b}$ & $0.614 \mathrm{~A}, \mathrm{a}$ & $0.373 \mathrm{AB}, \mathrm{ab}$ \\
\hline Ceramic & $0.225 \mathrm{~A}, \mathrm{a}$ & $0.246 \mathrm{~B}, \mathrm{a}$ & $0.381 \mathrm{AB}, \mathrm{a}$ & $0.282 \mathrm{AB}, \mathrm{a}$ \\
\hline Colorless & $0.407 \mathrm{~A}, \mathrm{ab}$ & $0.605 \mathrm{~A}, \mathrm{a}$ & $0.236 \mathrm{~B}, \mathrm{~b}$ & $0.205 \mathrm{~B}, \mathrm{~b}$ \\
\hline
\end{tabular}

Means followed by the same capital letter in the column and by the same small letter in the row do not differ statistically at a level of $5 \%$ of probability ( $<0.05)$, by Tukey's test.
Table 3 - Mean values of the color alteration readings of the test specimens $(\mathrm{n}=6)$ made with Silastic MDX4-4210 without pigment and with the three types of pigments, after the experimental aging periods.

\begin{tabular}{c|c|c|c|c}
\hline MDX & $163 \mathrm{~h}$ & $351 \mathrm{~h}$ & $692 \mathrm{~h}$ & $1,000 \mathrm{~h}$ \\
\hline Cosmetic & $0.267 \mathrm{~A}, \mathrm{c}$ & $0.365 \mathrm{~B}, \mathrm{bc}$ & $0.705 \mathrm{~A}, \mathrm{a}$ & $0.623 \mathrm{~A}, \mathrm{ab}$ \\
\hline Iron oxide & $0.316 \mathrm{~A}, \mathrm{a}$ & $0.389 \mathrm{~B}, \mathrm{a}$ & $0.460 \mathrm{AB}, \mathrm{a}$ & $0.350 \mathrm{AB}, \mathrm{a}$ \\
\hline Ceramic & $0.298 \mathrm{~A}, \mathrm{a}$ & $0.359 \mathrm{~B}, \mathrm{a}$ & $0.311 \mathrm{~B}, \mathrm{a}$ & $0.354 \mathrm{AB}, \mathrm{a}$ \\
\hline Colorless & $0.294 \mathrm{~A}, \mathrm{bc}$ & $0.911 \mathrm{~A}, \mathrm{a}$ & $0.460 \mathrm{AB}, \mathrm{b}$ & $0.156 \mathrm{~B}, \mathrm{c}$ \\
\hline
\end{tabular}

Means followed by the same capital letter in the column and by the same small letter in the row do not differ statistically at a level of $5 \%$ of probability $(p<0.05)$, by Tukey's test. 
sic and extrinsic factors. ${ }^{13}$ The intrinsic factors involve discoloration of the material itself with alterations in the matrix. ${ }^{14}$ Extrinsic factors, such as the absorption and adsorption of substances, also cause discoloration. ${ }^{15}$ Associated with this, other factors can cause color instability, such as accumulation of stains, dehydration, water absorption, infiltration, surface roughness, chemical degradation, degradation from use, oxidation during double carbon reactions to produce peroxide compounds, and continuous formation of pigments due to degradation of products. ${ }^{16}$

The spectrophotometric analysis revealed that the lowest values of color variation after 1,000 hours of aging were obtained by the non-pigmented test specimens (Tables 2, 3). This result indicates that both Silastic 732 and MDX4-4210 present satisfactory color stability and are indicated for clinic use $^{1,8,9,17-20}$ and that some physical and mechanical properties, such as color stability, can vary according to the addition of pigments.

Among the pigments, ceramic presented the lowest color alteration values and cosmetic powder presented the highest values (Tables 2, 3). This could be related to the size of the added particle or even to aging. It is known that silicone has a low level of cohesive energy and, therefore, a weak molecular interaction. Therefore, small particles tend to aggregate, but the larger ones separate from the polymer, and do not contribute to the reinforcement of the material. ${ }^{18}$ The constituent particles of the cos-

\section{References}

1. Kiat-Amnuay S, Mekayarajjananonth T, Powers JM, Chambers MS, Lemon JC. Interactions of pigments and opacifiers on color stability of MDX4-4210/type A maxillofacial elastomers subjected to artificial aging. J Prosthet Dent. 2006;95(3):24957.

2. Mancuso DN, Goiato MC, Dekon SFC, Gennari-Filho H. Visual evaluation of color stability after accelerated aging of pigmented and nonpigmented silicones to be used in facial prostheses. Indian J Dent Res. 2009;20:77-80.

3. Hanson MD, Shipman B, Blomfield JV, Janus CE. Commercial cosmetics and their role in the coloring of facial prostheses. J Prosthet Dent. 1983;50(6):818-20.

4. Kiat-Amnuay S, Lemon JC, Powers JM. Effect of opacifiers on color stability of pigmented maxillofacial silicone A-2186 metic powder are probably larger than the ceramic particles and, thus, are more easily separated from the polymer chain, which could cause higher color instability in these materials. Moreover, pigments of organic origin such as make-up powder undergo greater degradation with aging and end up dissolving when they come in contact with UV light. ${ }^{6,21}$

Further studies are important to evaluate the influence of other pigments on the color stability of materials normally used in clinical practice.

\section{Conclusion}

Based on the results obtained in the present study, it was concluded that:

- During spectrophotometric analysis, both Silastic 732 and MDX4-4210 presented color instability during the different periods of time analyzed.

- The materials without the incorporation of pigments presented similar color alteration values, and did not differ statistically.

- The cosmetic powder used in this study was the pigment that most altered the color of the test specimens.

\section{Acknowledgements}

The present study was based on a thesis submitted to the graduate faculty, São Paulo State University (UNESP), in partial fulfillment of the requirements for the MSc degree. This study was supported by The State of São Paulo Research Foundation (FAPESP), Brazil. subjected to artificial aging. J Prosthodont. 2002;11(2):10916.

5. Leow ME, Ow RK, Valiyaveettil S, Lee MH, Pho RW. Colourfast pigments in silicone hand and maxillofacial prostheses. Prosthet Orthot Int. 2002;26(2):124-34.

6. Gary JJ, Smith CT. Pigments and their applications in maxillofacial elastomers: A literature review. J Prosthet Dent. 1998;80(2):204-8.

7. Gary JJ, Huget EF, Powell LD. Accelerated color change in a maxillofacial elastomer with and without pigmentation. J Prosthet Dent. 2001;85(6):614-20.

8. Yu R, Koran IIIA, Craig RG. Physical properties of a pigmented silicone maxillofacial material as a function of accelerated aging. J Prosthet Dent. 1980;59(7):1141-8. 
9. Yu R, Koran III A, Craig RG. Physical properties of maxillofacial elastomers under conditions of accelerated aging. J Dent Res. 1980;59(6):1041-7.

10. Beatty MW, Mahanna GK, Dick K, Jia W. Color changes in dry-pigmented maxillofacial elastomer resulting from ultraviolet light exposure. J Prosthet Dent. 1995;74(5):493-8.

11. Lemon JC, Chambers MS, Jacobsen ML, Powers JM. Color stability of facial prostheses. J Prosthet Dent. 1995;74(6):6138.

12. Commission Internationale de l'Eclairage - CIE. Colorimetry, Official Recommendations of the International Commission on Illumination. $2^{\text {nd }}$ ed. Publication CIE No. 15.2 (TC-1.3). Paris, France: Bureau Central de la CIE; 1985.

13. Villalta P, Lu H, Okte Z, Garcia-Godoy F, Powers JM. Effects of staining and bleaching on color change of dental composite resins. J Prosthet Dent. 2006;95(2):137-42.

14. Wilson NH, Burke FJ, Mjor IA. Reasons for placement and replacement of restorations of direct restorative materials by a selected group of practitioners in the United Kingdom. Quintessence Int. 1997;28(4):245-8.
15. Satou N, Khan AM, Matsumae I, Satou J, Shintani H. In vitro color change of composite-based resins. Dent Mater. 1989;5(6):384-7.

16. Anil N, Hekimoglu C, Sahin S. Color stability of heat-polymerized and autopolymerized soft denture liners. J Prosthet Dent. 1999;81(4):481-4.

17. Andres CJ, Haug SP, Brown DT, Bernal G. Effects of environmental factors on maxillofacial elastomers: Part II - Report of survey. J Prosthet Dent. 1992;68(3):519-22.

18. Anusavice KJ. Phillips' science of dental materials. $11^{\text {th }}$ ed. St. Louis: Elsevier; 2003.

19. Craig RG, Koran A, Yu R, Spencer J. Color stability of elastomers for maxillofacial appliances. J Dent Res. 1978;57(910):866-71.

20. Lewis DH, Castleberry DJ. An assessment of recent advances in external maxillofacial materials. J Prosthet Dent. 1980;43(4):426-32.

21. Mayer R. The artist's handbook of materials and techniques. $5^{\text {th }}$ ed. New York: Viking Penguin; 1991. 